\title{
The Hidden Cost of Digital Immaturity
}

TO GAIN VALUABLE YOUNG CLIENTS, WEALTH MANAGERS MUST ADAPT

By David P. Wilson

Wealth managers have long understood that attracting younger high-networth clients is critical to the future success of advisory firms. Today, however, many managers risk missing a critical window of opportunity with the next generation of high-net-worth individuals (HNWIs). Recent survey data indicate wealth managers' misconceptions about the behaviors and preferences of younger HNW investors may cause managers to lose potential clients to competing providers, such as automated advisers. To avoid serious disruption of their business model, wealth managers must adapt in several important ways, especially by raising their level of digital maturity.

\section{A FRAGMENTED MARKET}

The past few years have been very good for HNWI wealth growth. When our firm, Capgemini, released its World Wealth Report 2016 (a benchmark for insights into the global wealth management industry and the 20th anniversary edition of the report), findings showed that global HNWI wealth expanded almost four-fold over the past 20 years, from US $\$ 16.6$ trillion in 1996 to US\$58.7 trillion in 2015. This remarkable growth came despite the Financial Crisis of 2008 and the largest contraction of wealth recorded since the Great Depression.

Another positive tailwind has been the return of trust to the industry. The Capgemini Global HNW Insights Survey, conducted in the first quarter of 2016 and spanning more than 5,200 HNWIs in 23 countries, observed large increases in the trust HNWIs have in nearly every aspect of the financial services business. This finding was especially true regarding the percentage of HNWIs globally who expressed trust and confidence in their primary wealth management firm, which increased 17 percentage points to $74 \%$.
Despite increased trust and record levels of wealth, however, the survey shows that wealth managers oversee less than one-third of global HNWI wealth. The picture is starker still when observing that primary wealth managers handle less than $22 \%$ of HNWI wealth. The takeaway is that wealth managers are falling short in their ability to attract a greater amount of HNWI assets.

\section{YOUTHFUL OPTIMISM}

Of the remaining two-thirds of HNWI wealth, roughly half is locked up in illiquid assets (including real estate and businesses) and thus will not present a shortterm opportunity for consolidation. But the wealth in illiquid assets will provide a medium-term opportunity as liquidity events arise. For wealth managers, a more immediate target of opportunity can be found in the largest chunk of the remaining wealth, representing more than one-third of the total, given it is essentially liquid and thus potentially available to wealth managers. Thirty-three percent of investable HNWI wealth is sitting in retail bank accounts or in the form of physical cash (Figure 1).

But younger HNWIs are even more inclined to allocate their wealth to bank accounts and cash rather than the services of wealth managers. They also appear to have more of their wealth tied up in their businesses than older HNWIs. Specifically, less than $28 \%$ of the wealth of under-40 HNWIs is held with wealth managers, compared with $42 \%$ for those HNWIs over 60 . Our view is that this finding is a significant challenge to wealth managers and firms alike. If the trend persists, it will be capable of imperiling the wealth management industry.

But there is some good news. HNWIs are willing to consolidate more of their assets with their primary wealth managers in the future. This willingness is even stronger (perhaps unsurprisingly so) among HNWIs who are satisfied, with $68 \%$ of such HNWIs willing to consolidate, compared with only $21 \%$ of those who are dissatisfied.

This situation also presents an opportunity for wealth managers. While HNWIs under 40 currently have a relatively low level of wealth booked with wealth managers, younger HNWIs are also the most open to the idea of consolidating their assets under a manager, with almost two-thirds stating they are likely to do so. The key, then, will be to offer a proposition that attracts them to the firm.

\section{MYTHS ABOUT YOUNGER HNWIS}

Being able to attract younger HNWIs is a critical success factor for the future. One phase is to attract these potential clients as they create wealth of their own, but another phase is to attract them as they inherit wealth (notably from the Baby Boomers in North America and Europe and from the first- and second-generation wealth creators in the emerging markets of Asia Pacific) over the coming decades.

But wealth managers have to overcome an obstacle of their own making. When wealth management firms look at attracting and serving younger HNWIs, they often base their strategies on the myth that younger HNWIs generally have simple wealth management needs and are only interested in using online services to fulfill their need for basic services. Our research has found this not to be the case at all; in fact, the financial planning needs and concerns of younger HNWIs are even more acute than those of older HNWIs. Such a mismatch is perhaps why we have consistently found that the satisfaction of younger HNWIs with their primary wealth managers lags that of clients who are 60 or older.

As a result, the demand for professional advice is very strong. For example, 
in our 2015 report we found that younger HNWIs globally are more worried than wealth managers realize about affording retirement, managing education costs, and passing down their wealth, among other areas. The primary concerns of younger HNWIs revolve around health and financial planning, including their own and their family's health $(69.9 \%$ stating a concern), fears around assets lasting through their lifetime (67.9\%), being able to afford the lifestyle they prefer in retirement (67.1\%), and the rising costs of healthcare (65.2\%). In contrast, wealth managers' assessment of the importance of these HNWI concerns is much lower, with a gap of 16 percentage points regarding family health, 18 points with respect to assets lasting a lifetime, 22 points regarding rising healthcare costs, and 19 points with respect to maintaining their lifestyle in retirement. There is also a considerable gap of 23 percentage points between younger HNWIs expressing high concern about rising education costs and wealth managers indicating that it is an important concern for clients.

\section{ACHIEVING DIGITAL MATURITY}

Attracting younger HNWIs involves two scenarios: (1) wealth transfer among generations and (2) wealth creation.
First, during wealth transfer, an oftenoverlooked fact is that in most cases the wealth does not pass directly from one person to another (e.g., from parent to child). Instead, wealth often passes among three people (e.g., from parent to spouse to child). Of course, such a three-stage transfer is likely to occur over a number of years. There is therefore a clear need to engage the full household as part of the overall wealth relationship in order to better serve the primary relationship. Just as a client planning for retirement requires optimized wealth distribution solutions, the spouse and next generation need to be prepared for the wealth transfer event. (This is also a chance to build intimacy and trust well in advance of their inheriting the assets.) Firms can and do go about engaging the full household in a variety of ways, from using multi-generational and multi-gender adviser teams to tailoring propositions for key solutions of interest to different clients (such as philanthropic causes) to hosting youth academies and other offsite events.

The second scenario where there is an opportunity to attract younger HNWIs relates to wealth creation. Younger HNWIs are active in the traditional wealth-creating engines of entrepreneurship and career earnings, but to gain younger wealth creators as clients, firms will need to have excellent prospecting tools that go beyond traditional referral models (which often rely on close-knit connections in a physical community) and embrace new social media technology. According to the 2016 Capgemini survey, $60.5 \%$ of wealth managers of all ages view prospecting through social media as the most important digital capability their firm can provide, and this number is closer to $70 \%$ among wealth managers under 40. It's worth noting, however, that this capability is also where satisfaction for clients lags the most, with the gap between importance and satisfaction reaching 17 percentage points, the largest of any capability surveyed.

Regardless of whether the scenario is wealth transfer or wealth creation, digital maturity packaged in an overall goals-based financial planning model will be critical to attracting and retaining the younger HNWI set. Firms cannot afford to fall short in any aspect of their digital strategy, as HNWIs hold digital capabilities to be important across informing (real-time portfolio information, portfolio evaluation, research), engaging (with wealth managers, exchanging documents), and

FIGURE 1:

Breakdown of Investable Wealth across Entities and Accounts (by Region), 012016

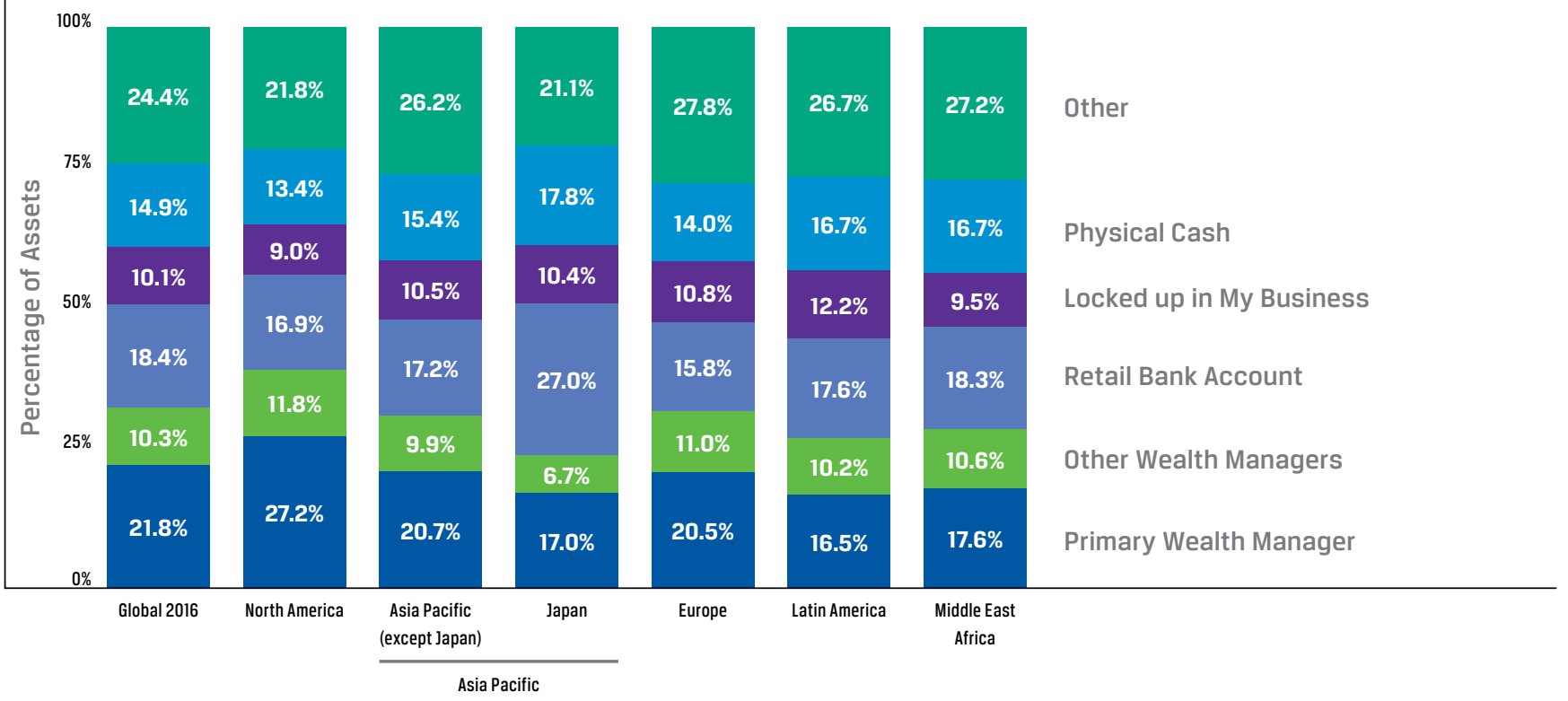

Sources: Capgemini Financial Services Analysis, 2016; Global HNW Insights Survey 2016, Capgemini

Notes: Question asked: "How does your investable wealth break down across entities and accounts?" Chart numbers may not add up to $100 \%$ due to rounding. Real estate is included as a part of "Other." 
transacting capabilities. Across all ages, wealth segments, and regions, there is a significant risk of HNWIs leaving a firm because of the lack of an integrated channel experience with digital capabilities. Further, $66.3 \%$ of HNWIs globally said that they would consider leaving firms that do not allow digital transactions. The greatest attrition risk comes from younger HNWIs; $50 \%$ of HNWIs under 40 said they would leave if there were no way to engage digitally, compared with $20.5 \%$ of those over 60 .

Given the magnitude of this challenge, our firm developed an assessment model in 2016 to help firms gauge and improve their level of digital maturity. Findings from the model indicate that the industry has achieved only a medium level of digital maturity, which will not be sufficient to tackle the high levels of digital demand that exist, especially from younger HNWIs.

The need to improve digital maturity levels is only going to intensify with the

\section{LESS THAN 28\% OF THE WEALTH OF UNDER-40 HNWIS IS HELD WITH WEALTH MANAGERS, COMPARED WITH 42\% FOR THOSE HNWIS OVER 60. ... IF THE TREND PERSISTS, IT WILL BE CAPABLE OF IMPERILING THE WEALTH MANAGEMENT INDUSTRY.}

ever-increasing penetration of non-traditional fintech firms into wealth management. The demand for automated advisers, for example, has been well reported, with wealth firms increasingly going from resistors to embracers of these models, either by building in-house or partnering with/acquiring automated advisers. That being said, the industry may not be fully aware of the extent of HNWI demand, given that $67 \%$ of HNWIs globally indicate a willingness to use automated advisers (compared with only $31 \%$ of wealth managers). Demand from younger HNWIs is even higher, at $82 \%$ of all HNWIs under 40 .

Of more concern for the industry is fintech's penetration among advice providers. Our survey shows that HNWIs are turning to digital peer-to-peer investment forums, swapping insight and information with peers through socalled open investment communities. Specifically, we saw that nearly half of HNWIs tap into online peer-to-peer networks at least weekly to find out about investment ideas, and another $26 \%$ use them monthly or quarterly. Usage is also set to expand, with $84 \%$ of younger HNWIs saying they expect to increase

\section{VOLUNTEER WITH THE DISCIPLINARY REVIEW COMMITTEE}

If you have an interest in helping to uphold ethical conduct in the investment profession and in protecting the CFA ${ }^{\circledR}$ charter, the Disciplinary Review Committee (DRC) would like to hear from you. The DRC, a committee of CFA charterholder volunteers, ajudicates disciplinary cases brought forth by the CFA Institute Professional Conduct Program.

The DRC is accepting nominations. Successful applicants should be CFA charterholders who have at least five years of professional experience, no prior or pending professional conduct issues, a fair and impartial temperament, and knowledge of or a desire to learn more about the disciplinary process of CFA Institute.

Please email DRCVolunteers@efainstitute.org to request an application. The application deadline is 28 February 2017.

For details, visit www.cfainstitute.org/ethics/conduct. 
their use of such networks over the next 12 months. Firms cannot delay in building digital maturity and business model innovation and positioning wealth managers as holistic, goals-based planners rather than investment managers.

Overall, the rise of automated advisers has had two different effects on wealth management. Although it led to commoditization of the more basic functions of investment management, automated advisers also have put a premium on those advisers able to deeply engage HNWIs and their families and bring a broad range of expertise to bear in the achievement of life goals. At the same time, the fintech trend is providing strong complementary digital capabilities that can help wealth managers attract and serve the future of wealth: the under-40 HNWI. In both cases, raising firms' level of digital maturity will be key, but simply adding technology functionality is not the goal; rather, firms need to focus on customer journeys and identify the digital capability needed to deliver differentiated experiences.

David P. Wilson is head of the Strategic Analysis Group at Capgemini Financial Services. He can be reached at david.p.wilson@ecapgemini.com or on Twitter [David_P_Wilson.

\section{The Volunteer's Journey}

While in Santa Monica, California, for his final meeting as a member of the CFA Institute Board of Governors this past July, James G. Jones, CFA, gave an eloquent farewell speech to the Board and Leadership Team. Fellow Board member George Spentzos, CFA, then read a moving parable Jones had written for the occasion to relate his experiences as a volunteer working with CFA Institute. Jones' story, printed below, represents the volunteer's journey as reported by our many valued CFA Institute members.

With hesitation and apprehension, the young man from the rural village cautiously approached the great city. He had heard of many wise and learned people who lived in this city and was perplexed as to why he had been invited to enter its gates. However, shortly upon entering the city, he met many fellow travelers who had received similar invitations. Though they were very different from him, he felt curiously drawn to them, and soon realized the outward differences of language, culture, and experience only momentarily masked the deeper similarities of sharp intellect, common interest, and shared conviction in hard work and high ethics.

In due time, the man was asked to participate in the care and building of the great city. The man took delight in the work, for he met many people who became his friends. Each friend had unique experiences and gifts the man came to recognize and appreciate. The days were filled with productive labor and the nights with good food, wine, and much laughter. Many times the man traveled to the remote parts of the great city-for it was very vast-and on every trip discovered new friends. After many years, the man was unexpectedly invited to help in the administration of the great city. This was a great honor and, although difficult at times, was the source of many more wonderful experiences.

One day, the man realized the day of his departure from the great city was approaching. He felt a growing sense of sorrow fill his heart at the thought of parting from his dear and true friends. The evening before his departure, a feast was held in the great hall of the city, and hours of laughter (and not a few tears) were shared. Stories of shared adventures were told, and oaths of affection were made. Late into the night, illuminated by the glow of the fire, the friends tarried, unwilling to part and hoping to delay the coming dawn. But at last, everyone retired for the night, and the great city became quiet.

Unable to bear the thought of parting in daylight, the man, having once returned to his room, gathered his pack and made his way to the gate of the city. He silently passed through the gate and began the long journey back to the rural village of his youth. Moonlight lit his way along the path, which led to the crest of a large hill. Upon reaching the crest, the man turned and looked back at the city one last time. Through misty eyes, he recognized the few bricks he had helped lay in the foundation of the city, parts of the wall he had helped repair, and a large tower that was still under construction but that he had helped design. These sights filled his heart with pride and a feeling of having made a contribution to the shaping of the great city.

As he turned to leave, the man noticed a small pool of still water alongside the stream that flowed beside the path. Kneeling down to drink, he was shocked to see a stranger's reflection in the water. He quickly turned and searched for the stranger, but there was no one to be found in the stillness of the moonlight. Slowly peering back into the pool, the man realized that the stranger's reflection was his own. His face was much older and wiser than when he had first arrived at the great city, but there were other differences, too, which he noted but could not immediately pinpoint.

After many hours of deep thought, a flicker of recognition crossed his troubled mind. The gesture of a hand, the turn of a phrase, the way he prepared his tea and held his fork, his broader perspectives and different ways of thinking-had these things not all first been seen in his dear friends? Joy flooded him. He had not left his friends. His friends had become a part of who he was. And he hoped he had left a part of himself with them. "Never shall I be without my friends," he cried. And his heavy heart was comforted.

Rising and turning back to the path, the man looked beyond the horizon toward his home and saw the first rays of morning light that marked the dawn of a new adventure.

James G. Jones, CFA, served on the Board of Governors of CFA Institute for 6 years and as a volunteer member for 21 years. He currently serves as managing member of Sterling Investment Advisors. 